\title{
Relational Research between China's Marine S\&T and Economy Based on RPGRA Model
}

\author{
Kedong Yin, Suyuan Li, and Xuemei Li \\ School of Economics, Ocean University of China, Qingdao 266100, China \\ Correspondence should be addressed to Xuemei Li; lixuemei@ouc.edu.cn \\ Received 28 February 2016; Accepted 26 June 2016 \\ Academic Editor: Peide Liu
}

Copyright (C) 2016 Kedong Yin et al. This is an open access article distributed under the Creative Commons Attribution License, which permits unrestricted use, distribution, and reproduction in any medium, provided the original work is properly cited.

\begin{abstract}
To make up the defect of the existing model, an improved grey relational model based on radian perspective (RPGRA) is put forward. According to the similarity of the relative change trend of time series translating traditional grey relational degree into radian algorithm within different piecewise functions, it greatly improves the accuracy and validity of the research results by making full use of the poor information in time series. Meanwhile, the properties of the RPGRA were discussed. The relationship between China's marine S\&T and marine economy is researched using the new model, so the validity and creditability of RPGRA are illustrated. The empirical results show that marine scientific and technological research projects, marine scientific and technological patents granted, and research funds receipts of the marine scientific research institutions have greater relationship with GOP, which indicates that they have more impact on China's marine economy.
\end{abstract}

\section{Introduction}

Introduction of Grey Relational Degree. Grey system theory (GST) [1], as well as fuzzy set theory [2] and rough set theory [3], is one of the most widely used theories to research on uncertain problems. These theories are developing rapidly in recent years. Take fuzzy set theory as an example; many scholars contributed to its development [4-9]. Compared with fuzzy set theory and rough set theory, GST has more advantages in "small sample and poor information" fields, and it can make more contribution to semi-complex uncertainty problems.

Grey relational analysis (GRA) is part of grey system theory, which is suitable for solving problems with complicated interrelationships between multiple factors and variables. This method has been widely used to solve the uncertainty problems under the discrete data and incomplete information. GRA is proposed to measure the degree of correlation between sequences by calculating their similarity or proximity. It is also the basis of grey system analysis, modeling, prediction, and decision-making. Recently, grey relational theory tends to be mature and it has emerged as an effective model to measure the correlation degree. After GRA was first put forward by Deng, more and more research on the GRA and its applications has been performed. There are some traditional correlation degrees such as the original Deng correlation degree [10], the absolute correlation degree [11], the relative correlation degree, and the comprehensive correlation degree [12]. At the same time, various improvements in correlation degree and its extension are cropping up, such as T's correlation degree [13], slope correlation [14], B's correlation degree [15], C's correlation degree [16], the general correlation degree, and many other new correlation degree models [17-22].

Recently, grey relational degree model is applied to more and wider fields such as three-dimensional space and panel data model, and it is also greatly improved. For example, a multidimensional correlation degree which extended grey absolute correlation degree based on matrix is proposed [23], an enhanced grey clustering analysis method based on accumulation sequences using grey relational analysis (AGRA) is put forward [24], and a three-dimensional grey interval relational degree model based on time, index, and scheme is established [25]. And grey relational analysis is combined with the Dumpster-Shafer theory of evidence [26]. At the same time, many scholars have improved GRA model from different perspectives. Seyed Hamid used the analytic network process (ANP) to deal with the interdependencies 
among the criteria and modified the traditional grey relational analysis (GRA) to better address the uncertainties inherent in supplier selection decisions [27]. Wu et al. introduced the fractional order grey relational degree to analyze the relationship between sci-tech input and the economic growth of China. They defined fractional order grey relational analysis (FGRA) based on a fractional order difference operator and discussed the effect of different orders on grey relational analysis [28]. Wu et al. proposed a grey relational analysis model of scientific research ability on music based on AHP. It selected out dominant indicators and recessive indicators to evaluate software features and hardware features [28]. Guo et al. developed a new method, based on the traditional GRA method, to overcome its limitation. In this sense, they used a different distance between two intuitionistic fuzzy numbers [29]. Li et al. proposed a new GCRA model and put forward grey accumulation generation relational analysis model based on grey exponential law (AGRA) for nonequidistance unequal-length (NDUL) sequences as research is required on nonequidistance unequal-length sequences [30-32]. Li et al. proposed an effectiveness evaluation method which is based on the combination of the improved grey relational degree and the analytic hierarchy process (AHP), aiming at the shortcoming that the calculation of the grey relational coefficient is influenced by the number of schemes and distinguishing coefficients, which causes inconsistency of the evaluation results in the traditional grey relational degree [33]. Huang et al. proposed the methodology of improved GRA to solve the problems that existed in model validation based on current GRA methods in view of the similarity and nearness between the simulations and flight-test time series (time-varying data) and it is proved that the improved model satisfies the four grey relational axioms [34]. And there are other modified GRA models and their applications [35-40].

In conclusion, many scholars have made contribution to the development of grey relational degree and these lectures deepen the improvement of GRA and GST; at the same time they also promote the research on uncertain problems. However, these GRA models are mostly based on the definition of distance, slope, and area. They do not break away from the limitations and research it from another perspective, which may cause disadvantages to research on some complex problems.

Introduction of China's Marine S\&T and Economy. Marine economy refers to the development, utilization, and protection of the marine industry activities. It is an essential national development strategy to promote marine economy and build China into a maritime power. In recent years, China's marine economy has been developing rapidly. As marine development report of China (2015) says, gross ocean product (GOP) in 2015 is 6467 billion yuan, which has an increase of $7 \%$ over the previous year, accounting for $9.6 \%$ of gross domestic product (GDP).

Marine science and technology included marine science and marine technology. Marine science is a science that studies various natural phenomena and processes in the sea and their changing regularity, including physical oceanography, biological oceanography, marine geology, and marine chemistry. Marine technology refers to the accumulated experience, skills, and equipment used in the marine development activities, including marine engineering technology, marine biotechnology, seabed mineral resources exploration technology, water resources development by technology, marine environment protection technology, marine observation technology, marine forecast prediction technology, and ocean information technology. It can be said that marine science and technology are the integration of traditional and modern high-tech in the marine field.

With the development of science and technology, marine science and technology play a more and more important role in marine economy. Many scholars have made research on the intrinsic relevance and interaction, and they have confirmed that marine science and technology play an important role in promoting the development of marine economy. Qiao and Zhu used the C-D production function development model, carried out empirical study on coastal area panel data of years 2000-2008, and finally concluded the following: the government input to ocean science and technology has the remarkable positive effect on marine economic growth [41]. Dai et al. used Stochastic Frontier Analysis (SFA) to measure the total factor productivity (TFP) index of marine S\&T, and Exploratory Spatial Data Analysis (ESDA) and Spatial Panel Econometric Models were applied to identify the temporal and spatial distribution pattern and influencing factors from 2006 to 2011 [42]. Zhai and Business used marine economy double logarithmic production function model for China's coastal marine economy with panel data; econometric analysis showed that the elasticity of marine capital, marine science and technology, and marine labor is positive [43]. Zhang et al. designed coupling parameter with coupled degree and coupled coordination degree to build the model of marine industrial aggregation and marine science and technology talents aggregation and put forward some measures of the collaborative development of two systems based on their current collaborative development situation [44]. Liu et al. calculated the marine science and technology transfer rate of our country in the period 2000-2012 based on the different scopes of the connotations and explored the appropriate method to calculate the marine science and technology transfer rate which is suitable for the current development situation in the oceanic field in China [45].

Research Motivation. Quantitative analysis of the relationship between marine S\&T and economy has great strategic significance to promote marine economy. General quantitative analysis methods need adequate data, but, due to the lag of marine economy research in China, relative data cannot meet the requirements. Fortunately, grey relational analysis is effectively used in this field because it is applicable whether the samples are enough or regular. However, on the other hand, GRA is not perfect and there is space for further development. For example, some models do not have the properties of parallelism, isotonicity, uniqueness, and symmetry. Even though some improvements have already been done by scholars, real innovation is hard to see because they are still based on the definition of distance, slope, and area. Under these backgrounds, a new model called grey 
relational analysis based on radian perspective (RPGRA) is proposed in this paper. This new model can effectively use the poor information in time series and can improve the accuracy and validity of the research results. RPGRA uses piecewise linear representation (PLR) to translate traditional grey relational degree into radian algorithm within different piecewise functions. What is more, RPGRA has the properties of normativity, uniqueness, and parallelism and can expand some existing models.

RPGRA translates traditional grey relational degree into radian algorithm by using PLR, a method to analyze the nonlinear system by analyzing the nonlinear characteristics as a piecewise linear approximation. The nonlinear curve is replaced by a straight line segment according to the different section. Zhang et al. proposed a measurement that the time series are represented approximately with a sequence of the included angles between a pair of neighboring line segments [46]. Ding et al. proposed a radian-distance which can reserve segment trend information when compared with the angledistance [47]. In a word, RPGRA is put forward on the base of the algorithm of radian-distance and traditional grey relational degree, and it is applied to analyze the relationship between China's marine S\&T and economy.

\section{Establishment and Properties of the RPGRA Model}

2.1. Establishment of the RPGRA Model. The basic idea of the RPGRA model is to calculate the grey relational degree according to the relative change trend of time series. Use PLR to translate traditional grey relational degree into radian algorithm within different piecewise functions. Then apply radian-distance algorithm into grey relational analysis to establish RPGRA model to calculate the grey relational degree.

Step 1 (transforming the original time series). Time series is one kind of typical discrete sequences, and it can be expressed in many ways using some methods. In this paper, time series will be expressed as the form of piecewise function based on the thought of PLR.

Therefore, the time series can usually be expressed as the following formula:

$$
\begin{aligned}
& X_{m}=\left\{\left(x_{m}\left(t_{1}\right), x_{m}\left(t_{2}\right)\right), \ldots,\left(x_{m}\left(t_{i-1}\right), x_{m}\left(t_{i}\right)\right), \ldots,\right. \\
& \left.\quad\left(x_{m}\left(t_{n-1}\right), x_{m}\left(t_{n}\right)\right)\right\},
\end{aligned}
$$

where $t_{i}$ denotes the observation time points; $m$ denotes the number of time series; $n$ denotes the number of observing time points in one series; $x_{m}\left(t_{i}\right)$ denotes the observation value of the $m$ th time series at $t_{i}$; and $\left(x_{m}\left(t_{i-1}\right), x_{m}\left(t_{i}\right)\right)$ denotes the line segment with the starting value and the final value (Figure 1).

Definition 1. Segmented radian (rad) is the radian of the angle (acute angle) between the straight line formed by two adjacent points in time series and timeline. Set rad is positive if the angle is in the first quadrant and it is negative if the angle is in the fourth quadrant.

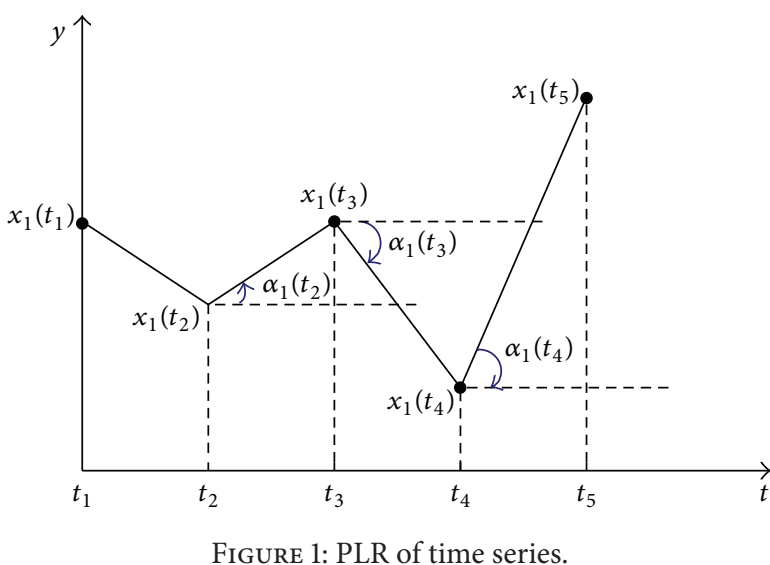

Definition 2. Before setting the radian time series, one should set angle series. Set the time series that can be expressed as $X_{m}=\left\{\alpha_{m}\left(t_{2}\right), \alpha_{m}\left(t_{3}\right), \ldots, \alpha_{m}\left(t_{n-1}\right)\right\}$, and one defines it as the corresponding angle series of the time series, where $n$ denotes the number of observing time points in one series and $\alpha_{m} t_{i}$ denotes the counterclockwise angle between the line segments $\left(x_{m}\left(t_{i-1}\right), x_{m}\left(t_{i}\right)\right)$ and $\left(x_{m}\left(t_{i}\right), x_{m}\left(t_{i+1}\right)\right)$ of the $m$ th time series.

Set

$$
\operatorname{rad}_{m}\left(t_{k}\right)=\arctan \frac{x_{m}\left(t_{k+1}\right)-x_{m}\left(t_{k}\right)}{\Delta t} .
$$

And it is the radian time series.

Step 2 (calculating the radian variation). Assume the interval is $[p, q]$, and then set the following formula as the variation function of the corresponding radian series from $t_{k-1}$ to $t_{k}$ :

$$
y_{m}\left(t_{k}\right)=\operatorname{rad}_{m}\left(t_{k}\right)-\operatorname{rad}_{m}\left(t_{k-1}\right) \quad k=1,2, \ldots, n-2 .
$$

Step 3. It is calculating the grey relational coefficient.

Definition 3. Assume that $X_{0}=\left\{x_{0}\left(t_{1}\right), x_{0}\left(t_{2}\right), \ldots, x_{0}\left(t_{n}\right)\right\}$ and $X_{i}=\left\{x_{i}\left(t_{1}\right), x_{i}\left(t_{2}\right), \ldots, x_{i}\left(t_{n}\right)\right\}(i=1,2, \ldots, m)$ are sequences in $[p, q]$, respectively; the following formula will be defined to calculate the relational coefficient between these two time series:

$$
\xi_{0 i}(k)=\frac{1}{1+\left|y_{0}\left(t_{k}\right)-y_{i}\left(t_{k}\right)\right|} .
$$

In order to effectively distinguish the grey relational coefficient generated by two different time series, a comparative variable is introduced into formula (4), which is the subtraction variable $\left|y_{0}\left(t_{k}\right)-y_{i}\left(t_{k}\right)\right|$. When the variation function of two time series in each $\Delta t_{k}$ is similar, the comparative variable will tend to be 0 , and then $\xi_{0 i}(k)$ will tend to be 1 and vice versa. 
TABLE 1: Original data: added value of strategic marine emerging industries. Unit: 100 million yuan/item.

\begin{tabular}{|c|c|c|c|c|c|c|}
\hline Year & $\begin{array}{c}\text { Gross ocean } \\
\text { product }\end{array}$ & $\begin{array}{l}\text { Marine scientific } \\
\text { research } \\
\text { institutions }\end{array}$ & $\begin{array}{l}\text { Research funds receipts } \\
\text { of the marine scientific } \\
\text { research institutions }\end{array}$ & $\begin{array}{l}\text { Marine scientific } \\
\text { and technological } \\
\text { research projects }\end{array}$ & $\begin{array}{l}\text { Marine scientific } \\
\text { theses published }\end{array}$ & $\begin{array}{c}\text { Marine scientific } \\
\text { and technological } \\
\text { patents granted }\end{array}$ \\
\hline 2006 & 21592.4 & 136 & 528.93 & 6593 & 8492 & 379 \\
\hline 2007 & 25618.7 & 136 & 773.94 & 7617 & 9104 & 398 \\
\hline 2008 & 29718 & 135 & 876.97 & 8327 & 9485 & 441 \\
\hline 2009 & 32277.6 & 186 & 160.16 & 12600 & 14451 & 1250 \\
\hline 2010 & 39572.7 & 181 & 1955.08 & 13466 & 14296 & 1482 \\
\hline 2011 & 45496 & 179 & 2322.19 & 14253 & 15547 & 2034 \\
\hline 2012 & 50045.2 & 177 & 2577.23 & 15403 & 16713 & 2746 \\
\hline 2013 & 54313 & 175 & 2655.64 & 16331 & 16284 & 3430 \\
\hline
\end{tabular}

Source from 2006 2014 China Marine Statistical Yearbook.

Definition 4. Assuming that $X_{0}=\left\{x_{0}\left(t_{1}\right), x_{0}\left(t_{2}\right), \ldots, x_{0}\left(t_{n}\right)\right\}$ and $X_{i}=\left\{x_{i}\left(t_{1}\right), x_{i}\left(t_{2}\right), \ldots, x_{i}\left(t_{n}\right)\right\}$ are nonnegative sequences in $[p, q]$, then

$$
\xi_{0 i}=\frac{1}{p-q} \sum_{k=1}^{n-2} \Delta t_{k} \cdot \xi\left(t_{k}\right)
$$

is named the grey relational degree of the RPGRA of $X_{0}$ and $X_{i}$. The greater $\xi_{0 i}$ is, the stronger the correlation between $X_{0}$ and $X_{i}$ is.

\subsection{Property of RPGRA}

Theorem 5. The properties of the model of RPGRA are as follows:

(1) $\left|\xi_{0 i}\right| \leq 1$.

(2) Symmetry, $\xi_{0 i}=\xi_{i 0}$.

(3) Uniqueness and independence, $\xi_{0 i}$ being unique for two fixed sequences and not influenced by other sequences.

(4) Comparability.

Proof. (1) We can obtain $\operatorname{rad}_{m}\left(t_{k}\right) \in(-\pi / 2, \pi / 2)$ from Definition 1 , so $-1<y_{m}\left(t_{k}\right)<1 \Leftrightarrow-1 \leq \xi_{0 i}\left(t_{k}\right) \leq 1$, $i=1,2, \ldots, m, k=2,3, \ldots, n$, and $[p, q]=\bigcup_{k=1}^{n-2} \Delta t_{k} \Leftrightarrow-1 \leq$ $\xi_{0 i}=(1 /(q-p)) \sum_{k=2}^{n} \Delta t_{k} \cdot \xi_{0 i}\left(t_{k}\right) \leq 1$.

(2) According to the definitions of the grey relational coefficient and the grey relational degree of the RPGRA, property (2) is obvious.

(3) The grey relational coefficient and the grey relational degree of the RPGRA are only connected with the two sequences involved. Once the sequences are determined, the radians are determined. Therefore, $\xi_{0 i}$ of certain sequences are confirmed and are not affected by other sequences in the system.

(4) This property is also correct due to property (3).

Theorem 6. Assume that there are two time series, $X_{0}=$ $\left\{x_{0}\left(t_{1}\right), x_{0}\left(t_{2}\right), \ldots, x_{0}\left(t_{n}\right)\right\}$ and $X_{i}=\left\{x_{i}\left(t_{1}\right), x_{i}\left(t_{2}\right), \ldots\right.$, $\left.x_{i}\left(t_{n}\right)\right\}(i=1,2, \ldots, m)$, and their grey relational degree is $\xi_{0 i}$, which satisfies $\left|\xi_{0 i}\right| \leq 1$ and $\xi_{0 i}=1$, if and only if $X_{i}\left(t_{k}\right)=$ $X_{0}\left(t_{k}\right)+c(k=1,2, \ldots, n, c$ is a constant $)$; then $X_{0}$ and $X_{i}$ are parallel; that is, the RPGRA model satisfies the normativity of GST.

Proof. As $\left|\xi_{0 i}\right| \leq 1$ and $\xi_{0 i}=1 \Leftrightarrow \xi_{0 i}\left(t_{k}\right)=1 \Leftrightarrow y_{0}\left(t_{k}\right)=$ $y_{i}\left(t_{k}\right) \Leftrightarrow \operatorname{rad}_{0}\left(t_{k}\right)-\operatorname{rad}_{0}\left(t_{k-1}\right)=\operatorname{rad}_{i}\left(t_{k}\right)-\operatorname{rad}_{i}\left(t_{k-1}\right) \Leftrightarrow$ $\operatorname{rad}_{0}\left(t_{k}\right)-\operatorname{rad}_{0}\left(t_{1}\right)=\operatorname{rad}_{i}\left(t_{k}\right)-\operatorname{rad}_{i}\left(t_{1}\right) \Leftrightarrow \operatorname{rad}_{i}\left(t_{k}\right)=$ $\operatorname{rad}_{0}\left(t_{k}\right)-\operatorname{rad}_{0}\left(t_{1}\right)+\operatorname{rad}_{i}\left(t_{1}\right) \Leftrightarrow \operatorname{rad}_{i}\left(t_{k}\right)=\operatorname{rad}_{0}\left(t_{k}\right)+c \Leftrightarrow$ $X_{i}\left(t_{k}\right)=X_{0}\left(t_{k}\right)+c \Leftrightarrow X_{0}, X_{i}$ are parallel. And $c=\operatorname{rad}_{i}\left(t_{1}\right)-$ $\operatorname{rad}_{0}\left(t_{1}\right)$.

That is, the model of RPGRA satisfies the characteristic of GRA's normativity. So this property was proved.

\section{Application of the RPGRA Model for Relationship between China's S\&T and Economy}

In recent years, China's marine economy has been developing rapidly, and marine science and technology have attracted high attention from concerned governmental departments. According to the China Marine Statistical Yearbook, the investment of marine science and technology has been increasing with the years. In 2013, the research funds receipts of the marine scientific research institutions are 265563 million yuan, increasing $200 \%$ from 2008. The research of China's S\&T is still in the initial stage. There are few data and they are mainly from China Marine Statistical Yearbook. Taking the choice of variables by scholars in Introduction and the availability of data into comprehensive consideration, five variables are selected to represent China's S\&T to research their correlation with marine economy. They are the number of marine scientific research institutions, research funds receipts of the marine scientific research institutions, the number of marine scientific and technological research projects, the number of marine scientific theses published, and the number of marine scientific and technological patents granted.

3.1. Empirical Analysis on Correlation between China's Marine S\&T and Economy. The original data of China's marine science and technology and gross ocean product (GOP) are shown in Table 1.

Use formula (2) to get the radian time series as Table 2. 
TABLE 2: The corresponding radian series of the original time series.

\begin{tabular}{lcccccc}
\hline Items & & \multicolumn{3}{c}{$\operatorname{rad}_{m}\left(t_{k}\right)$} \\
& $\operatorname{rad}_{m}\left(t_{2}\right)$ & $\operatorname{rad}_{m}\left(t_{3}\right)$ & $\operatorname{rad}_{m}\left(t_{4}\right)$ & $\operatorname{rad}_{m}\left(t_{5}\right)$ & $\operatorname{rad}_{m}\left(t_{6}\right)$ & $\operatorname{rad}_{m}\left(t_{7}\right)$ \\
\hline Gross ocean product & 1.5705 & 1.5706 & 1.5704 & 1.5707 & 1.5706 & 1.5706 \\
Research institutions & 0.0000 & -0.7854 & 1.5512 & -1.3734 & -1.1071 & -1.1071 \\
Research funds receipts & 1.5708 & 1.5708 & -1.5708 & 1.5708 & 1.5708 & 1.5708 \\
Research projects & 1.5698 & 1.5694 & 1.5706 & 1.5696 & 1.5695 & 1.5699 \\
Theses published & 1.5692 & 1.5682 & 1.5706 & -1.5643 & 1.5700 & 1.5708 \\
Patents granted & 1.5182 & 1.5475 & 1.5696 & 1.5665 & 1.5690 & 1.5697 \\
\hline
\end{tabular}

TABLE 3: Correlation coefficient of China's marine science and technology.

\begin{tabular}{|c|c|c|c|c|c|c|}
\hline \multirow{2}{*}{ Items } & \multicolumn{6}{|c|}{$\xi\left(t_{k}\right)$} \\
\hline & $\xi\left(t_{1}\right)$ & $\xi\left(t_{2}\right)$ & $\xi\left(t_{3}\right)$ & $\xi\left(t_{4}\right)$ & $\xi\left(t_{5}\right)$ & $\xi\left(t_{6}\right)$ \\
\hline Research institutions & 0.5601 & 0.2997 & 0.2548 & 0.7897 & 0.9999 & 1.0000 \\
\hline Research funds receipts & 1.0000 & 0.2415 & 0.2415 & 1.0000 & 0.9999 & 1.0000 \\
\hline Research projects & 0.9996 & 0.9987 & 0.9988 & 0.9999 & 0.9995 & 0.9998 \\
\hline Theses published & 0.9990 & 0.9974 & 0.2418 & 0.2419 & 1.0000 & 0.2416 \\
\hline Patents granted & 0.9715 & 0.9783 & 0.9967 & 0.9975 & 0.9995 & 1.0000 \\
\hline
\end{tabular}

Use formulas (3) and (4) to calculate $\xi\left(t_{k}\right)$ as Table 3. Use GOP as a basic sequence to calculate the correlation coefficient of the five variables for China's marine science and technology.

According to formula (5), $\xi_{0 i}$ is calculated as follows:

$$
\begin{aligned}
& \xi_{01}=\frac{1}{p-q} \sum_{k=1}^{n-2} \Delta t_{k} \cdot \xi\left(t_{k}\right)=0.6507, \\
& \xi_{02}=\frac{1}{p-q} \sum_{k=1}^{n-2} \Delta t_{k} \cdot \xi\left(t_{k}\right)=0.7471, \\
& \xi_{03}=\frac{1}{p-q} \sum_{k=1}^{n-2} \Delta t_{k} \cdot \xi\left(t_{k}\right)=0.9994, \\
& \xi_{04}=\frac{1}{p-q} \sum_{k=1}^{n-2} \Delta t_{k} \cdot \xi\left(t_{k}\right)=0.6203, \\
& \xi_{05}=\frac{1}{p-q} \sum_{k=1}^{n-2} \Delta t_{k} \cdot \xi\left(t_{k}\right)=0.9906 .
\end{aligned}
$$

The RPGRA degree between GOP and marine scientific and technological research projects is 0.9994, ranked first; the degree of marine scientific and technological patents granted is 0.9906 , ranked second; the degree of research funds receipts of the marine scientific research institutions is 0.7471, ranked third; the degree of marine scientific research institutions is 0.6507 , ranked fourth; and the degree of marine scientific theses published is 0.6203 , ranked the last. The value of grey relational degree does not have practical significance, so the results of empirical analysis are only concerned with the ranking and do not rigidly adhere to the value.

3.2. Conclusion of Empirical Analysis. According to the empirical results, GOP and marine scientific and technological research projects have a greater correlation degree, marine

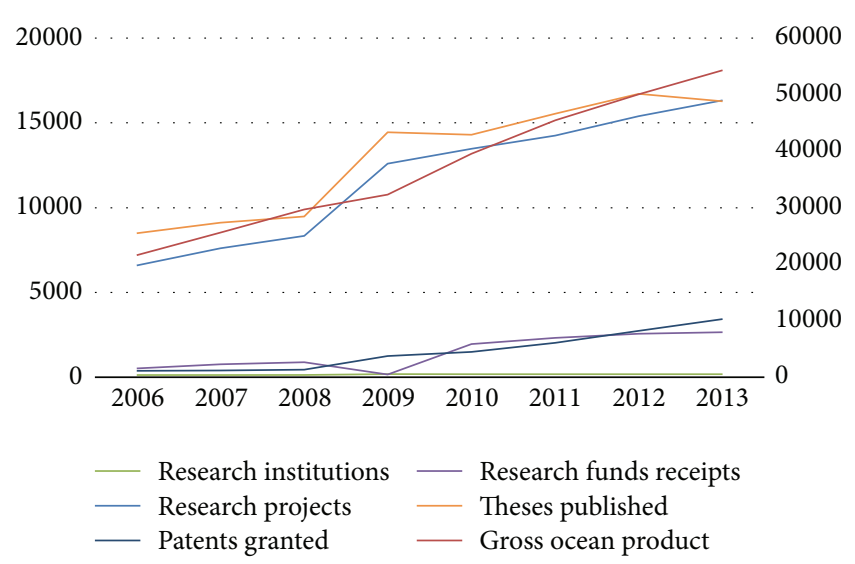

FIgURE 2: Diagrams of China's marine science and technology. Source from 2006 2014 China Marine Statistical Yearbook. Note. Only the gross ocean product uses the secondary coordinate.

scientific and technological patents granted take the second place, followed by research funds receipts of the marine scientific research institutions, and the degree of marine scientific theses published is the last one. The geometric figure of four variables and GOP is shown in Figure 2. From the trend we can see that GOP and research funds receipts, patents granted, and research projects have the most similar trend and have the least similarity with research institutions, which conform to the results of the empirical analysis and illustrate the effectiveness of RPGRA model.

3.3. Comparative Analysis with Traditional Grey Relational Methods. In this part, some traditional GRA models are also used to make comparative analysis. We use RPGRA degree, Deng's correlation degree, absolute correlation degree, relative correlation degree, and comprehensive correlation degree. The calculation result and ranking result are shown as Tables 4 and 5 . 
TABLE 4: Grey relational degrees of different methods.

\begin{tabular}{|c|c|c|c|c|c|}
\hline \multirow[b]{2}{*}{ Degree } & \multicolumn{4}{|c|}{ Methods } & \multirow[b]{2}{*}{$\begin{array}{l}\text { Comprehensive } \\
\text { correlation degree }\end{array}$} \\
\hline & RPGRA degree & $\begin{array}{c}\text { Deng's correlation } \\
\text { degree }\end{array}$ & $\begin{array}{c}\text { Absolute } \\
\text { correlation degree }\end{array}$ & $\begin{array}{c}\text { Relative correlation } \\
\text { degree }\end{array}$ & \\
\hline \multicolumn{6}{|l|}{ Items } \\
\hline Research institutions & 0.6507 & 0.8706 & 0.5009 & 0.6752 & 0.5880 \\
\hline Research funds receipts & 0.7471 & 0.7410 & 0.5299 & 0.7161 & 0.6230 \\
\hline Research projects & 0.9994 & 0.9687 & 0.6688 & 0.9562 & 0.8125 \\
\hline Theses published & 0.6203 & 0.9325 & 0.6485 & 0.8887 & 0.7686 \\
\hline Patents granted & 0.9906 & 0.6734 & 0.5347 & 0.6355 & 0.5851 \\
\hline
\end{tabular}

TABLE 5: Ranking results of the grey relational degree of different methods.

\begin{tabular}{|c|c|c|c|c|c|}
\hline \multirow[b]{2}{*}{ Ranking results } & \multicolumn{4}{|c|}{ Methods } & \multirow[b]{2}{*}{$\begin{array}{l}\text { Comprehensive } \\
\text { correlation degree }\end{array}$} \\
\hline & RPGRA degree & $\begin{array}{c}\text { Deng's correlation } \\
\text { degree }\end{array}$ & $\begin{array}{c}\text { Absolute } \\
\text { correlation degree }\end{array}$ & $\begin{array}{c}\text { Relative correlation } \\
\text { degree }\end{array}$ & \\
\hline \multicolumn{6}{|l|}{ Items } \\
\hline Research institutions & 4 & 3 & 5 & 4 & 4 \\
\hline Research funds receipts & 3 & 4 & 4 & 3 & 3 \\
\hline Research projects & 1 & 1 & 1 & 1 & 1 \\
\hline Theses published & 5 & 2 & 2 & 2 & 2 \\
\hline Patents granted & 2 & 5 & 3 & 5 & 5 \\
\hline
\end{tabular}

By analysis and calculation, the ranking results are variant in different methods. But, in general, the top one of the rankings is research funds receipts, and the number of research institutions ranks in the last two, which indicates RPGRA model's validity and creditability. The empirical results show that marine scientific and technological research projects, marine scientific and technological patents granted, and research funds receipts of the marine scientific research institutions have a greater correlation with GOP, which indicates that they have more impact on China's marine economy.

Marine scientific and technological research projects include five parts: basic research, applied research, experimental development, result application, and scientific and technological service. The number of marine research projects has increased 96\% from 2008 and its development situation is shown as Table 6 . Research projects can promote the investigation of marine research and resources, the construction of marine ecological civilization, and maintenance of maritime rights and interests. And they can also enhance the national marine awareness, improve the capacity of marine infrastructure and equipment, and then serve and promote the development of marine economy. In the next phase of the work, State Oceanic Administration will accelerate the research projects about construction of marine power, marine integrated management, maintenance of the marine rights and interests, and marine legislation.

Marine scientific and technological patents of the research include the number of patent applications accepted and the number of patents granted, and in this paper we use the number of patents granted because only it can reflect the patent of marine science and technology in our country accurately and objectively. Intellectual property is the product of the commodity economy and the development of science and technology. As one of the forms of intellectual property protection, patent plays an important role in the development of science and technology. The number of marine scientific and technological patents has increased $30 \%$ compared with last year, and the number is still growing rapidly.

Research funds receipts of the marine scientific research institutions include routine fund and loans in the government investment in the capital construction scientific and technological activities. The investment scale and structure of scientific research funds are shown as Figure 3. We can see that routine fund accounts for the largest proportion, while loans and government investment occupy little floor. Therefore, the investment scale and structure are not reasonable and they are an important factor affecting the conversion of science and technology achievements. Furthermore, due to its high correlation with marine economy, it may affect the further development of marine economy.

\section{Conclusions and Policy Recommendations}

The RPGRA model was established based on the similarity of the relative change trend of time series and on a new radian perspective. Then it is applied to analysis of China's marine S\&T and marine economy. The grey relational degree between marine S\&T index and economy reflects its position and function in marine economy. Index with greater correlation degree will have a greater impact on the development of the marine economy. Relevant data of marine S\&T is chosen to analyze the relationship between China's marine 
TABLE 6: Development situation of marine scientific and technological research projects. Unit: item.

\begin{tabular}{|c|c|c|c|c|c|c|}
\hline Year & $\begin{array}{c}\text { Number of } \\
\text { research projects }\end{array}$ & Basic research & Applied research & $\begin{array}{l}\text { Experimental } \\
\text { development }\end{array}$ & Result application & $\begin{array}{l}\text { Scientific and } \\
\text { technological service }\end{array}$ \\
\hline 2008 & 8327 & 2087 & 2623 & 1420 & 691 & 1506 \\
\hline 2009 & 12600 & 2753 & 3338 & 2550 & 1074 & 2885 \\
\hline 2010 & 13466 & 3104 & 3497 & 2838 & 1359 & 2668 \\
\hline 2011 & 14253 & 3476 & 3696 & 2855 & 1453 & 2773 \\
\hline 2012 & 15403 & 3756 & 3854 & 3569 & 1515 & 2709 \\
\hline 2013 & 16331 & 4276 & 3735 & 3997 & 1516 & 2807 \\
\hline
\end{tabular}

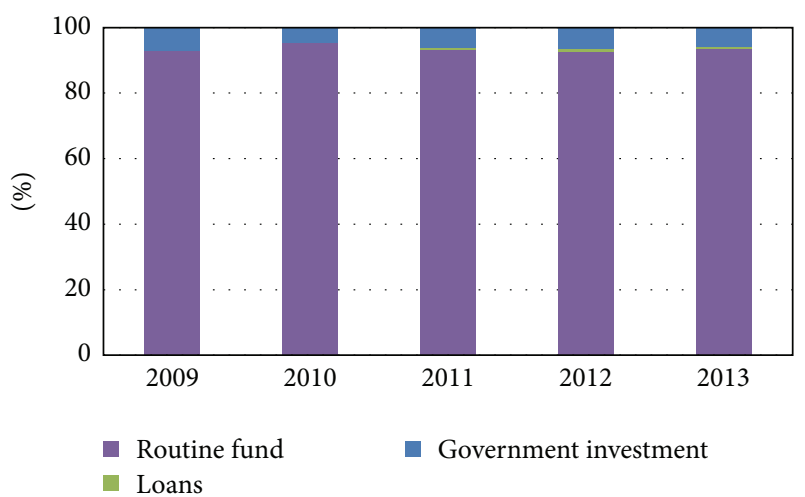

FIGURE 3: Diagrams of investment scale and structure of scientific research funds.

S\&T and marine economy. The empirical results show that marine scientific and technological research projects, marine scientific and technological patents granted, and research funds receipts of the marine scientific research institutions have greater correlations with GOP, which indicates that they have more impact on China's marine economy.

Therefore, China needs to develop marine S\&T especially in research projects, patents, and research funds to promote marine economy and so as to make the economy more prosperous. We need to further refine the National Marine Economy Development Plan to realize the sustainable development of marine economy in China and build China into a maritime power.

\section{Competing Interests}

The authors declare that they have no competing interests.

\section{Acknowledgments}

The relevant researches done in this paper are supported by the National Social Science Fund Major Projects (14ZDB151); General Financial Grant from the China Postdoctoral Science Foundation (2015M580611); Qingdao Postdoctoral Application Research Project Funding (251); and Fundamental Research Funds for the Central Universities (201613006, 201564031).

\section{References}

[1] J. L. Deng, "Introduction to grey system theory," The Journal of Grey System, vol. 1, no. 1, pp. 1-24, 1989.
[2] L. A. Zadeh, "Fuzzy algorithms," Information \& Control, vol. 12, no. 2, pp. 94-102, 1968.

[3] Z. Pawlak, "Rough sets," International Journal of Computer \& Information Sciences, vol. 11, no. 5, pp. 341-356, 1982.

[4] P. Liu, L. He, and X. Yu, "Generalized hybrid aggregation operators based on the 2-dimension uncertain linguistic information for multiple attribute group decision making," Group Decision and Negotiation, vol. 25, no. 1, pp. 103-126, 2016.

[5] P. D. Liu, Y. Li, and J. Antuchevičiene, "A multi-criteria decisionmaking method based on intuitionistic trapezoidal fuzzy prioritized OWA operator," Technological and Economic Development of Economy, vol. 22, no. 3, pp. 453-469, 2016.

[6] P. Liu, "Some generalized dependent aggregation operators with intuitionistic linguistic numbers and their application to group decision making," Journal of Computer and System Sciences, vol. 79, no. 1, pp. 131-143, 2013.

[7] P. Liu and F. Jin, "A multi-attribute group decision-making method based on weighted geometric aggregation operators of interval-valued trapezoidal fuzzy numbers," Applied Mathematical Modelling, vol. 36, no. 6, pp. 2498-2509, 2012.

[8] P. Liu, X. Zhang, and F. Jin, "A multi-attribute group decisionmaking method based on interval-valued trapezoidal fuzzy numbers hybrid harmonic averaging operators," Journal of Intelligent and Fuzzy Systems, vol. 23, no. 5, pp. 159-168, 2012.

[9] P. Liu, "Some geometric aggregation operators based on interval intuitionistic uncertain linguistic variables and their application to group decision making," Applied Mathematical Modelling, vol. 37, no. 4, pp. 2430-2444, 2013.

[10] J. L. Deng, "Relational space of grey theory," Fuzzy Mathematics, vol. 4, no. 2, pp. 1-10, 1985.

[11] Z. G. Mei, “The concept and computation method of grey absolute correlation degree," System Engineering, no. 05, pp. 4344, 1992.

[12] S. F. Liu, Y. G. Dang, Z. G. Fang et al., Grey System Theory and Application, Science Press, Beijing, China, 2012.

[13] W. X. Tang, "The concept and the computation method of T's correlation degree," Application of Statistics and Management, no. 01 , pp. 34-37, 1995.

[14] Y. G. Dang, "Research on grey relational analysis of slope," System Sciences and Comprehensive Studies in Agriculture, vol. 10, pp. 331-337, 1994.

[15] Z. L. Wang and Q. Y. Wang, "Some properties of Grey B-related degree," Journal of Hebei Mining and Civil Engineering Institute, no. 3, pp. 48-50, 1992.

[16] X. H. Zhao and Q. Y. Wang, "The relational analysis of C-mode," Journal of Huazhong University of Science and Technology, vol. 27, no. 3, pp. 75-77, 1999. 
[17] H. X. Shi, S. F. Liu, Z. G. Fang et al., "The model of grey periodic incidence and their rehabilitation," Chinese Journal of Management Science, vol. 3, pp. 131-136, 2008.

[18] H. Y. Du, H. X. Shi, S. F. Liu et al., "Study on the model of grey periodic incidence judged on slope," Chinese Journal of Management Science, no. 01, pp. 128-132, 2010.

[19] H. J. Xiong, M. Y. Chen, and T. Qu, "Some extensions of grey relational grade formula," Systems Engineering and Electronics, no. 1, pp. 8-10, 2000.

[20] Y. G. Dang, S. F. Liu, B. Liu et al., "Improvement on degree of grey slope incidence," Engineering Science, vol. 6, no. 3, pp. 4144, 2004.

[21] Y. G. Sun and Y. G. Dang, "Improved model of slope grey relational analysis," Statistics and Decision, no. 15, pp. 12-13, 2007.

[22] Y.-G. Sun and Y.-G. Dang, "Improvement on grey T's correlation degree," System Engineering Theory and Practice, vol. 28, no. 4, pp. 135-139, 2008.

[23] K. Zhang and S.-F. Liu, "Extended clusters of grey incidences for panel data and its application," System Engineering-Theory \& Practice, vol. 30, no. 7, pp. 1253-1259, 2010.

[24] X. Li, K. W. Hipel, and Y. Dang, "An improved grey relational analysis approach for panel data clustering," Expert Systems with Applications, vol. 42, no. 23, pp. 9105-9116, 2015.

[25] Y. Wang, X. Shi, J. Sun, and W. Qian, "A grey interval relational degree-based dynamic multiattribute decision making method and its application in investment decision making," Mathematical Problems in Engineering, vol. 2014, Article ID 607016, 6 pages, 2014.

[26] Z. Li, G. Wen, and N. Xie, "An approach to fuzzy soft sets in decision making based on grey relational analysis and Dempster-Shafer theory of evidence: an application in medical diagnosis," Artificial Intelligence in Medicine, vol. 64, no. 3, pp. 161-171, 2015.

[27] S. H. Hashemi, A. Karimi, and M. Tavana, "An integrated green supplier selection approach with analytic network process and improved Grey relational analysis," International Journal of Production Economics, vol. 159, pp. 178-191, 2015.

[28] F. L. Wu, F. S. Liu, G. L. Yao et al., "Fractional order grey relational analysis and its application," Scientia Iranica, vol. 22, no. 3, pp. 1171-1178, 2015.

[29] X. Guo, Y. Ni, and Wangjia, "A grey relational analysis model of scientific research ability on music based on AHP and its realization," International Journal of Signal Processing Image Processing \& Pattern Recognition, vol. 8, no. 5, pp. 211-222, 2015.

[30] G.-W. Wei, "Gray relational analysis method for intuitionistic fuzzy multiple attribute decision making," Expert Systems with Applications, vol. 38, no. 9, pp. 11671-11677, 2011.

[31] X. M. Li, Y. G. Dang, and L. Jin, "Grey trend analysis based on grey relational degree with rate of change and its application," Chinese Journal of Management Science, vol. 23, no. 9, pp. 132138, 2015.

[32] X. Li, Y. Dang, L. Jin, and W. Kang, "GCRA model for grey trend analysis and its application," Journal of Grey System, vol. 27, no. 1, pp. 57-69, 2015.

[33] X. M. Li, Y. G. Dang, S. Ding, and J. Zhang, "Grey accumulation generation relational analysis model for nonequidistance unequal-length sequences and its application," Mathematical Problems in Engineering, vol. 2014, Article ID 764857, 8 pages, 2014.
[34] G. Q. Huang, W. B. Zhao, and S. H. Xu, "A combination method of improved grey relational degree and AHP for effectiveness evaluation," in Proceedings of the 3rd International Conference on Mechatronics and Information Technology, 2016.

[35] X. L. Ning, W. U. Ying-Xia, Y. U. Tian-Peng et al., "Research on comprehensive validation of simulation models based on improved grey relational analysis," Systems Engineering \& Electronics, vol. 32, no. 8, pp. 1677-1679, 2016.

[36] N. Xie, Y. Han, and Z. Li, "A novel approach to fuzzy soft sets in decision making based on grey relational analysis and MYCIN certainty factor," International Journal of Computational Intelligence Systems, vol. 8, no. 5, pp. 959-976, 2015.

[37] W. Wu and Y. Peng, "Extension of grey relational analysis for facilitating group consensus to oil spill emergency management," Annals of Operations Research, vol. 238, no. 1-2, pp. 615635, 2016.

[38] K. Guo and Q. Zhang, "Detecting communities in social networks by local affinity propagation with grey relational analysis," Grey Systems: Theory and Application, vol. 5, no. 1, pp. 31-40, 2015.

[39] X. Liu and T. Liu, "Blasting parameters optimization based on grey relational analysis," Gansu Metallurgy, no. 2, pp. 1-3, 2016.

[40] N. Wang, S. X. Zhang, and J. Cao, "Application of Grey relational analysis in evaluation of cross-fault deformation anomaly interference factors," Journal of Seismological Research, vol. 38, no. 1, pp. 90-98, 2012.

[41] J. Qiao and J. Zhu, "Government input to ocean science and technology and marine economic growth: empirical study based on panel data," Science and Technology Management Research, no. 4, pp. 37-40, 2012.

[42] B. Dai, G. Jin, and M. Han, "Analysis on temporal and spatial evolution of marine science and technology total factor productivity and its influencing factors in Chinese coastal areas," Geographical Research, vol. 34, no. 2, pp. 328-340, 2015.

[43] R. X. Zhai and S. O. Business, "Marine science and technology investment and marine economic growth: an empirical study with panel data in China's coastal regions," Mathematics in Practice \& Theory, no. 4, pp. 75-80, 2014.

[44] X. X. Zhang, P. F. Zhang, and X. U. Zi-Yi, "The coupling evaluation model of China's marine industrial aggregation and marine science and technology talents aggregation," Journal of Shandong University, no. 6, pp. 118-128, 2014.

[45] D. Liu, X. Li, C. Wang et al., "Calculating and forecasting of marine science and technology transfer rate," Marine Economy, vol. 5, no. 2, pp. 18-22, 2015.

[46] P. Zhang, X.-R. Li, J.-Y. Zhang, and Z.-L. Zhang, "Included angle distance of time series and similarity search," Pattern Recognition and Artificial Intelligence, vol. 21, no. 6, pp. 763-767, 2008.

[47] Y. W. Ding, X. H. Yang, A. J. Kavs et al., "Similarity measure of time series based on radian distance," Journal of Electronics and Information, no. 1, pp. 122-128, 2011. 


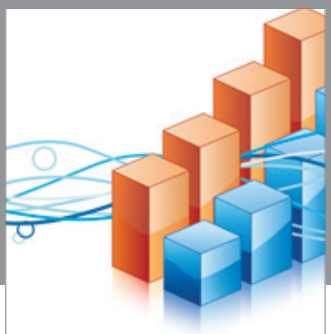

Advances in

Operations Research

vatem alat4

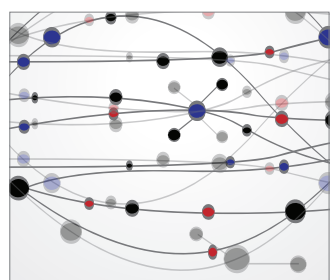

\section{The Scientific} World Journal
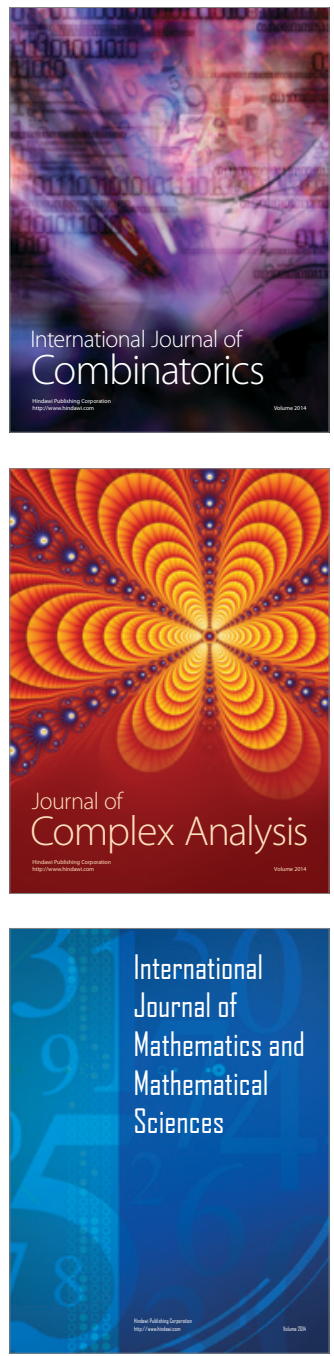
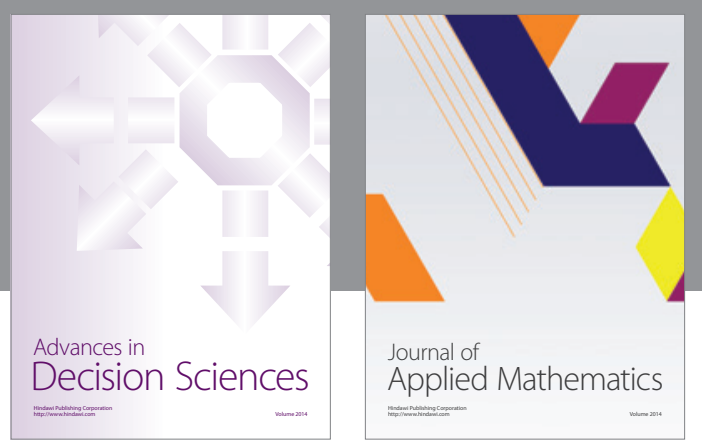

Algebra

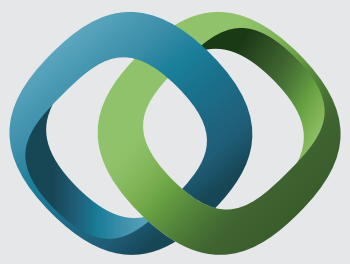

\section{Hindawi}

Submit your manuscripts at

http://www.hindawi.com
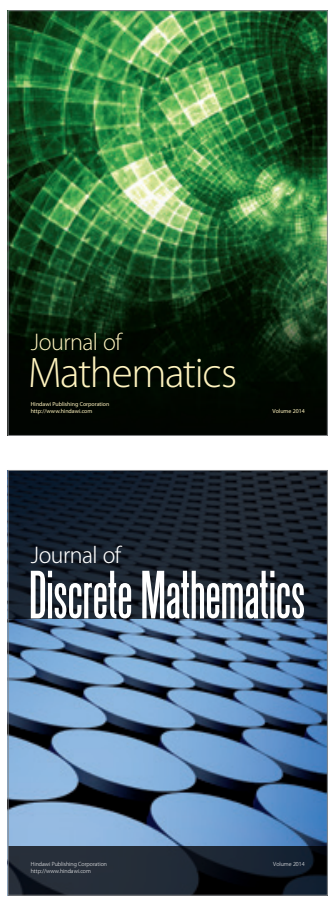

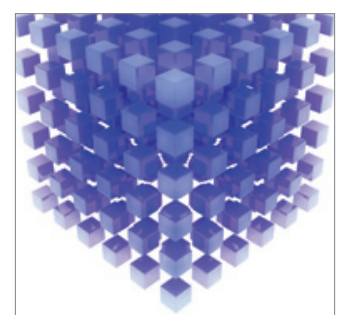

Mathematical Problems in Engineering
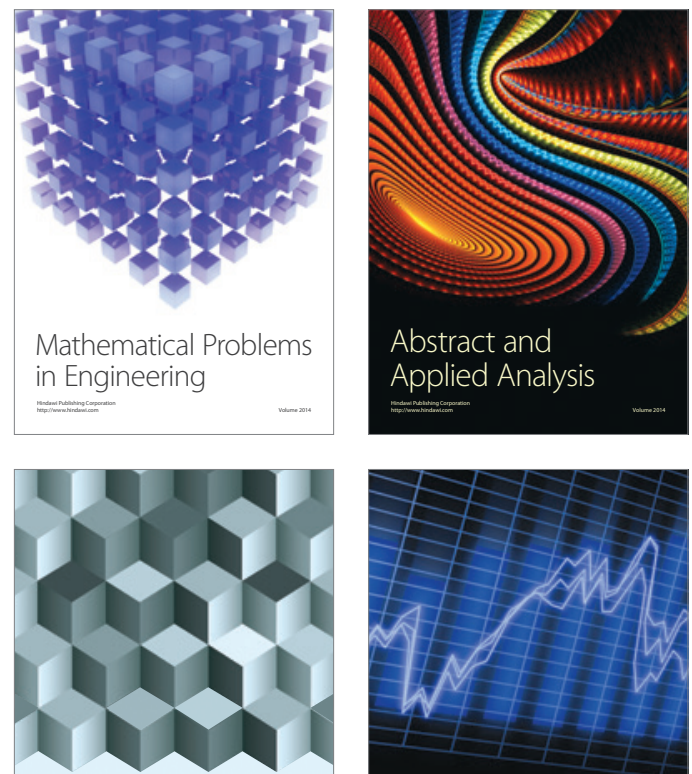

Journal of

Function Spaces

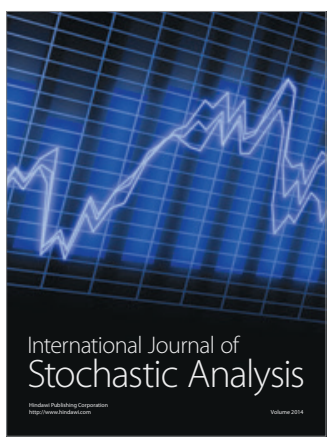

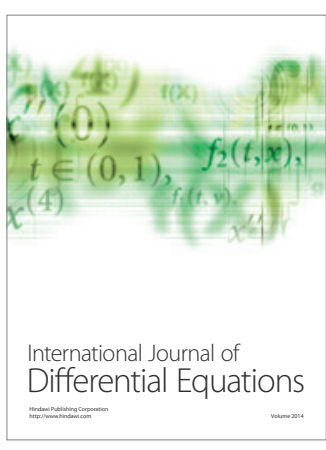
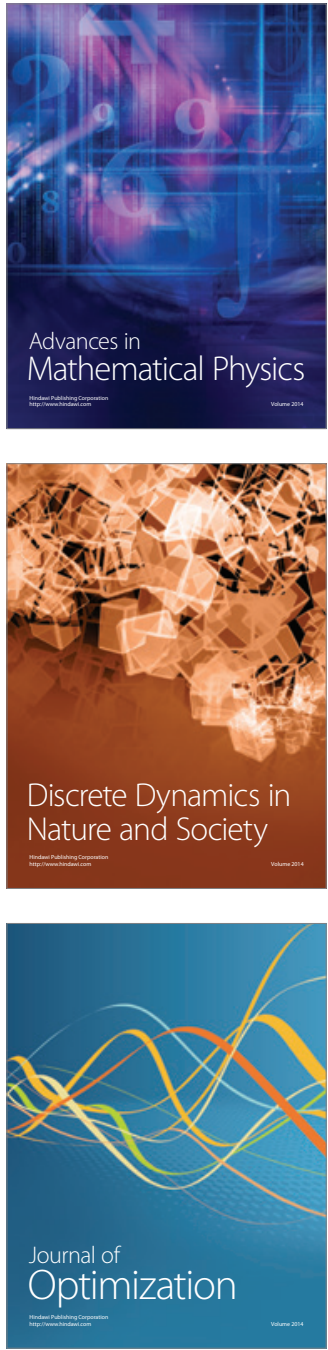